\title{
India's Neemrana Industrial Park for Japanese Firms
}

\subsection{Introduction}

India is second only to China in terms of population. India's economic growth since the mid-2000s has risen to around $8 \%$, and is now considered as having a promising future market. However, the driving force behind this economic growth is the country's service industry, particularly its IT service industry. As compared to China, India trails in its growth in the manufacturing industry. One reason for this gap is the lack of infrastructure in India. For a manufacturing industry to grow, basic infrastructure, such as power and water, and logistics facilities, such as roads, railways, and ports for imports and exports, are required. However, infrastructure development in India has not progressed as planned. Half of India's population is under the age of 25 , resulting in a relatively low average age. Therefore, creation of employment opportunities for this younger generation is important. For this reason, it is necessary to promote the manufacturing industry having a high employment absorption capacity. Infrastructure creation is thus an important policy issue for the Indian government.

The Neemrana Industrial Park for Japanese firms was created with the cooperation of the Japanese government and the state government of Rajasthan, situated to the southwest of Delhi. This project has become a highly anticipated one even within the Indian government. Industries in Rajasthan have focused on agriculture and mining such as for marble and cement. The relative lag in industrialization has motivated the Rajasthan state government to provide incentives to factories to set up operations such as automotive industries having high employment absorption capacity. On the other hand, India carries a relatively higher investment risk for Japanese companies for a variety of reasons than do other nearby Asian countries, such as China. These companies find themselves forced to make investment decisions based on insufficient decision-making information, for example, the accessibility of infrastructure such as power and water necessary to operate factories, availability of efficient and appropriate workers, or the ability to adequately respond 
to various central or local government regulations and directives. Maruti Suzuki and Honda, which together comprise more than $40 \%$ of India's passenger cars, operate factories near Delhi and have strong incentives to attract parts and materials manufacturers to India to strengthen cost competitiveness. Against this backdrop, Japan's External Trade Organization (JETRO) has taken the lead in outfitting the industrial parks to lure, primarily, Japanese auto-related companies to India, thereby reducing risks that individual companies otherwise could not handle.

\subsection{Background of Neemrana Industrial Park}

The Neemrana Industrial Park is located in the state of Rajasthan, and is approximately $105 \mathrm{~km}$ southwest of Delhi's Indira Gandhi International Airport (a $90 \mathrm{~min}$ drive). The Park faces National Highway 8, connecting Delhi and Mumbai. With the establishment of Phase III (1,166 acres), it will be the first in India to be developed specifically for Japanese companies (Fig. 6.1).

India has pursued industrial decentralization policies aiming to balance development since the 1970s by providing industrial location guidance to underdeveloped and unindustrialized regions. In addition to the Delhi Special Area, the center of development since the latter half of the 1980s, development plans have expanded in the neighboring states of Uttar Pradesh (UP), Haryana, and Rajasthan (in part), all of which comprise the National Capital Region (NCR). These plans aim to relieve overpopulated conditions in the capital and decentralize economic activities.

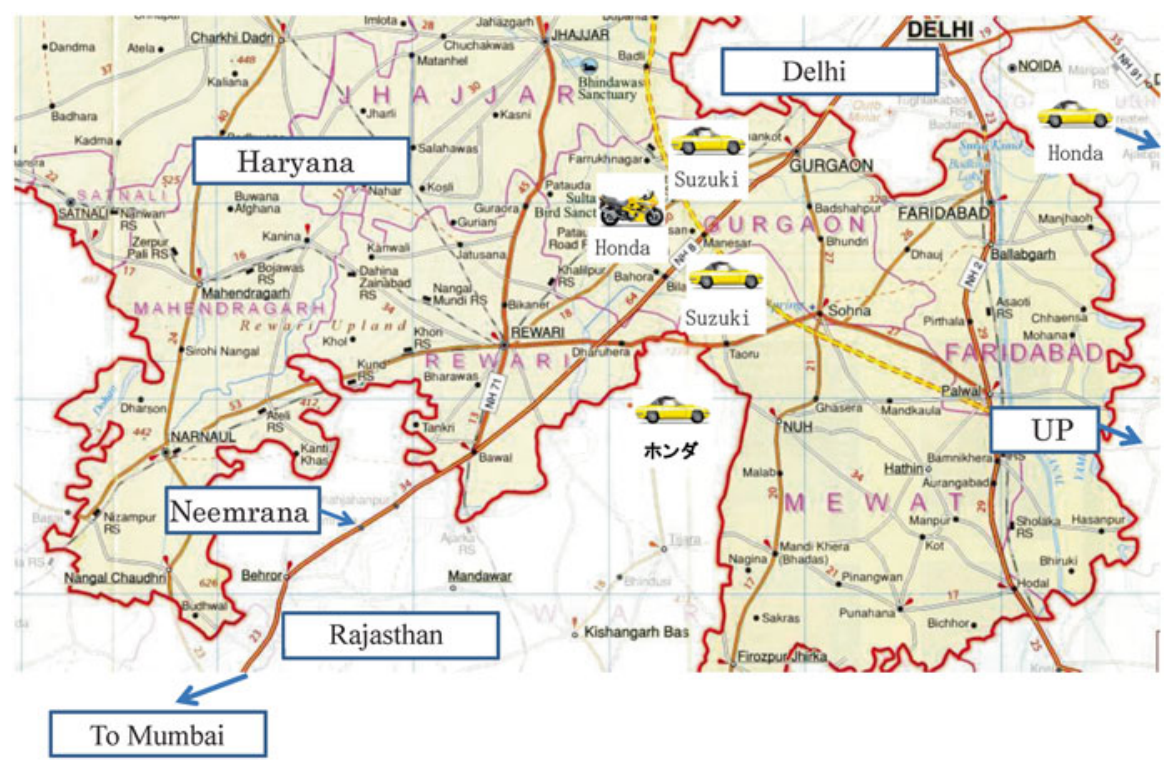

Fig. 6.1 Map of Neemrana Industrial Park and surrounding area 
The NCR is a planned area adjacent to Delhi and is based in seven centers (Gurgaon, Faridabad, Noida, Ghaziabad, Sonipat, Greater Noida, and Meerut) located along the National Highways radiating outward from Delhi. It is near consumer markets centered in Delhi, and is a valuable base for the expansion of the Northern Indian market. Being based near the capital has many other advantages, such as better communication with government and other enterprises as well as procuring excellent labor. The nexus of industrial development is the industrial parks, and developmental corporations under the control of each state's department of industries are responsible for the purchase, establishment, and sale of properties in the parks.

The Noida Business Park, situated in UP, is the largest industrial park in the NCR, and has been under development since 1976. Phase I saw the participation of smaller companies, while Phases II and III saw the participation of medium-sized companies. Plans to proceed with medium- and large-sized factories in this region, made up primarily of foreign auto makers, necessitated vast open spaces, and thus the Greater Noida industrial park was developed at a distance of about 10-15 km southeast of Noida. The foray of automakers into Greater Noida spurred the expansion of the auto parts market, thus currently making this region the greatest agglomeration of auto industry companies. Suzuki (passenger cars in 1983) and Honda (motorcycles in 1984) built factories in Gurgaon, Haryana, during the 1980s. Gurgaon is located to the southwest of Delhi, making it possible to procure parts from nearby areas of Noida and Greater Noida, resulting in this region also having an agglomeration of auto industry companies.

In India today, Suzuki and Honda procure $80-90 \%$ of parts locally, although this figure applies only to finished vehicles. Japanese parts manufacturers in India that supply to automakers, procure approximately $60 \%$ of their raw materials internationally. It is becoming more difficult, even within India, to compete in price, as low-cost cars such as the "Nano" made by Tata Motors are causing a stir with its INR 100,000 (about JPY 200,000) price tag. There is an increasing necessity for Japanese manufacturers to procure not only first-tier parts, but also second- and even third-tier parts from local sources in the future to enable price competitiveness through cost reduction. Automakers await the entry of second- and third-tier Japanese parts suppliers into India, and when they do, these suppliers will need land for factories. These parts manufacturers are oftentimes small- and medium-sized firms, with low manpower or capital, making it difficult to independently enter the Indian market. Thus, JETRO's initiative is essential by kicking off projects to build industrial parks for Japanese companies.

The issue is primarily location based. With sudden farmland expropriations to develop industrial parks, land prices have risen in Noida and Greater Noida in the state of UP. JETRO approached Faridabad and Gurgaon in the state of Haryana, but industrial parks have already been developed in these regions, causing land prices to skyrocket. Therefore, the state of Rajasthan, which had missed the development wave, came under JETRO's radar. Rajasthan was originally a kingdom (name derived from "raja" or king and "stan" or country) with territories ruled over by a maharaja (a powerful king), today it is said to have a citizenry with an earnest 
nature. Vasundhara Raje, of the Bharatiya Janata Party (BPJ), became the first female chief minister of the state in 2003 proves the change. Chief Minister Raje was very popular among those in the industry and had a reputation for being a wise and decisive leader. Further momentum for industrialization was gained by the aggressive efforts of the Chief of Industries in the Raje cabinet. The managing director of the Rajasthan State Industrial Development \& Investment Corporation Ltd. (RIICO), a believer in the promotion of industrial development and having a deep understanding of economic development in China, enabled agreements with Japan to proceed smoothly.

RIICO created a Japan Desk, and appointed Anil Sharma as general manager. Mr. Sharma notes the characteristics of the state of Rajasthan as an ideal location for industry operations: "The laws and systems are well put together for India as a whole, compared with developing nations. India is a democracy, and laws and systems don't change according to the whims of government. Also, contracts are seen as things to be honored. Next, we have an abundant workforce. There have been 76 engineering firms established in the state of Rajasthan in the last 15 years, and the state has produced a tremendous number of IT and software-related companies. An Industrial Training Institute (ITI) has also been established to develop factory workers. Third, the electric power infrastructure is well developed compared with Haryana and Punjab near Delhi. Finally, there is policy support. Much support is given to lure industry here through RIICO."

In regards to land, the plan has always been to sell property with RIICO as the landowner, causing the appropriation to be free of problems often inherent with complex land ownership. Another important factor was that this land was, for the most part, a desert, and therefore not appropriate for agricultural use. All 1,166 acres of Phase III of the Neemrana Industrial Park sitting alongside National Highway 8, in Rajasthan was provided as an industrial park for Japanese companies. In July 2006, the Japanese government requested the state government of Rajasthan for (1) priority purchase rights for Japanese companies over a 2 year period (which in 2008 was extended for another year) and (2) a reduction in the state border tax (from 4 to $0.25 \%$ ). In that same month, JETRO and RIICO entered into a memorandum of understanding (MOU) to jointly support a "campaign to facilitate Japanese investment". For the first 6 months, not many companies were convinced to set up operations in Rajasthan, but with the Indian government's focus on infrastructure development to lure foreign (particularly Japanese) companies, the campaign became a Japanese-Indian "Delhi Mumbai Industrial Corridor Project" (DMIC); these efforts came to be more broadly known.

\subsection{DMIC: Delhi Mumbai Industrial Corridor}

The Neemrana Industrial Park was an early bird project part of the larger DMIC project. It was an important joint Japan-India industry promotion proposal.

The DMIC “is a joint Japan-India project for a major industrial area connecting industrial parts and ports via freight railways and roads between Delhi and Mumbai, 
for the purpose of promoting foreign investment and exports." (JETRO Delhi "DMIC concept explanatory material, December 2009") By constructing approximately $1,500 \mathrm{~km}$ of new freight railways between the interior political capital of Delhi and the industrial port city of Mumbai, it attempts to invigorate the Indian industry by outfitting the railway as its key traffic route, by building industrial parks, interior distribution facilities, and new ports along the railway corridor. Preparations for a high-speed railway scheduled for completion in 2016 are underway, and the Japanese government has committed toward contributing construction capital out of Official Development Assistance (ODA) funds (Fig. 6.2).

This is a massive Indian project involving six states (Haryana, UP, Rajasthan, Madhya Pradesh, Gujarat, and Maharashtra) and multiple government organizations (state departments of commerce, offices of chief ministers, planning committees, departments of finance, infrastructure-related departments). The DMIC Development Corporation (DMICDC) was established in January 2008 as a panstate special purpose development organization. The development of the DMIC Master Plan was completed in 2010, outlining a grand concept for constructing a total of 24 industrial cities across the six states by 2030. With acceleration of urbanization among the Indian population, it is estimated that $40 \%$ of India's total population will live in urban areas by 2030 . Because of this, the DMIC Master Plan calls for the job creation through construction of industrial parks and for the urban

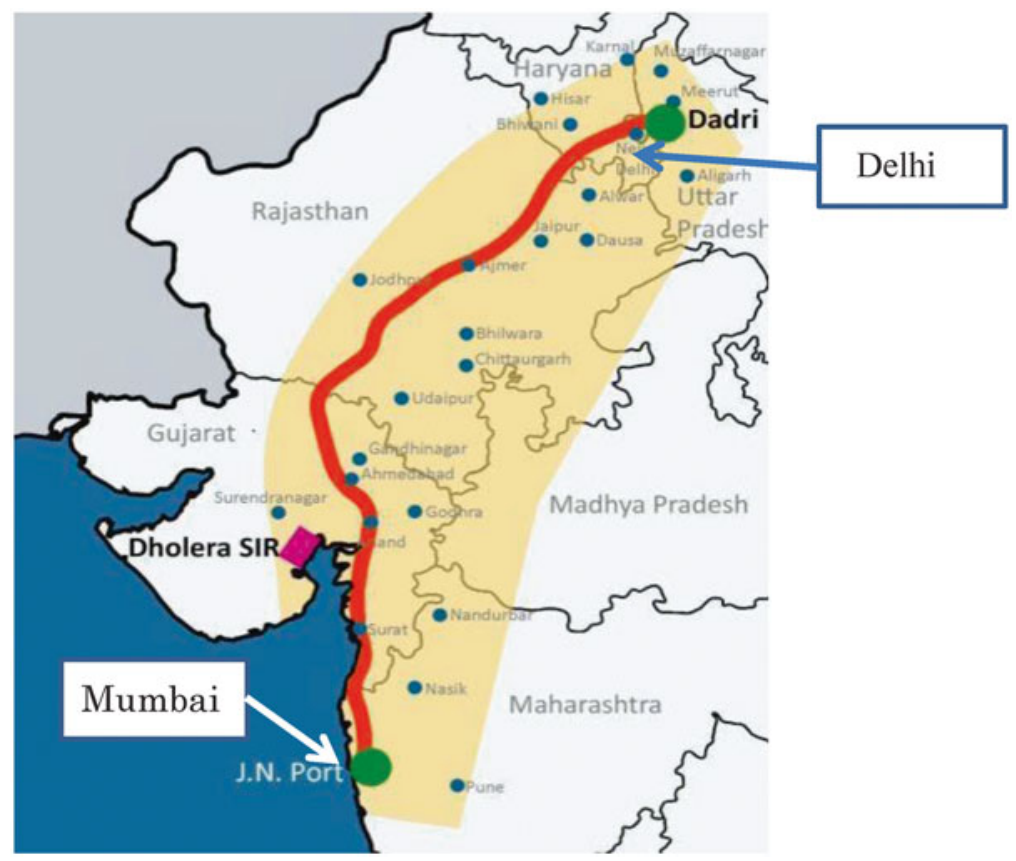

Fig. 6.2 Map of DMIC and High-Speed Railway (Source: JETRO Delhi materials from DMIC) 
development of surrounding regions as residential areas. The DMICDC oversees all these projects and assumes the role of developer in concert with state governments.

In India, the management of land not owned by citizens is the responsibility of state governments. Accordingly, actual urban development is carried out by state governments providing land to Special Purpose Companies (SPCs), which finance the DMIC project through funds to develop each urban area. Projects that have a high potential for commercialization, such as electric power projects, are undertaken as Public-Private Partnerships (PPPs), with the expectation of joint public private financing. Projects of a more public nature, such as roads and water services, are managed directly by the SPCs as public works projects.

However, these development plans are still in their conceptual stages, and funding will be necessary from the Indian government to proceed with future urban development. Also, the 24 new cities outlined by the Master Plan are, for the most part, to be established in vacant areas. It is unlikely that companies will set up operations in industrial parks with low infrastructure, and with no companies in hand to occupy an industrial park, private companies will be slow to invest in infrastructure.

It will take considerable time to carry out development according to the DMIC Master Plan, even though early bird development projects have been set up in advance of finalizing the Master Plan. The Neemrana Industrial Park is one such project, and a smart factory project bolstered by the Japanese government is also moving forward, as explained later. Another early bird project is a free trade and warehousing zone planned for construction in the state of Haryana by Mitsui Bussan. This will create an inland container depot (ICD) to directly transport containers via high-speed railroads from ports to the ICD, and will enable customs clearance in inland areas. There are currently two ICDs, Dadri in Uttar Pradesh, and Tughlakabad in Delhi, although according to the DMIC Master Plan another ICD is expected to be built near Neemrana. The high-speed railway will not only be used to supply parts from Mumbai to Delhi, but is anticipated to significantly contribute toward regional economic development due to its role as the key distribution channel connecting the two large cities of Northern India and the medium-sized cities along its pat

\subsection{India's Industrial Infrastructure}

Before explaining the details of the Neemrana Industrial Park, below is a quick overview of the infrastructure necessary for setting up manufacturing sites in India.

First are roadways, which are one method for overland transport. Most national highways, including National Highway 8 connecting Delhi and Mumbai, are twolane drives, on which trucks, motorcycles, auto rickshaws, bicycles, livestock, and pedestrians commute. Accordingly, traffic is often congested and high-speed transport is impossible. 
India ranks fourth in the world in terms of railway length, with a total of $633,332 \mathrm{~km}$. However, only $28 \%$ of these are electricity operated and only $25 \%$ are double-tracked. Freight cars travel at a speed of only $23 \mathrm{~km} / \mathrm{h}$ and although travel fares are low, freight shipments are expensive. Thus, it is cheaper to transport goods by truck.

The Indian federal government manages 12 main ports: Kandla, Mumbai, Jawaharlal Nehru, Mormugao, New Mangalore, Cochin, Tuticorin, Chennai, Ennore, Vishakhapatnam, Paradip, and Kolkata. These ports together handle 464 mn tons annually. Ports under the jurisdiction of state and local governments are termed as "non-major ports" (or "minor ports"). These ports handle a total of 160 mn tons annually. Northern India, which has no coastline, relies on container shipments from gateway ports in the western part of the country. India's western ports handle $69 \%$ of all container freight.

Stable electric power supply is another requirement for an industrial park. In 2010, electric power demand in India was $8.5 \mathrm{mn}$ gigawatt-hour (GWh), an increase of more than six percent over the last 5 years. Peak electricity demand is estimated to increase as high as $120 \mathrm{GW}$, driving overall demand far higher than the country's supply capacity of approximately one $\mathrm{mn} \mathrm{GWh}$. In addition, issues related to high transmission and distribution loss rates and theft of electric power decrease the electric power availability for those who need it, making power outages a frequent occurrence. One reason for this is the strain on power company fee schedules. Fee schedules are constrained by low (or free) rates for farmers, which are offset by industries paying relatively higher fees, resulting in a cross subsidy of sorts. Companies pay high power bills to run their factories, and work with the frequent power outages and shortages. It is therefore common for large-scale factories to have in-house power generation.

Due to low groundwater levels and water contamination, water shortages are common in Northern India. In an attempt to limit the overuse of groundwater and promote its restoration, the Indian government has asked all states to enact rainwater harvesting laws (regulations that mandate the return of water to nearby regions if groundwater usage in that region is in excess of rainwater in the region). Regions around Delhi have plans for constructing water desalination plants; however, there are as yet no prospects for solving water shortages.

\subsection{Companies Operating at Neemrana Industrial Park}

As of March 2012, 14 companies have set up operations in the Neemrana Industrial Park (Phase III for Japanese firms). While there were some cancelations by companies that had planned to set up, particularly during the economic downturn on account of the Lehman Brothers bankruptcy, site sales in the Park have since recovered is at almost full occupancy as of 2012. Companies in the Park (and those planning to set operations) hold regular meetings to share information, during which they discuss issues and solutions for building and operating factories, as well as compile requests to the state government and RIICO. These combined requests are 
more effective rather than an independent request. In addition, receiving approval from the administration can be extremely complicated, requiring the use of a local consultant at certain circumstances. Even in these cases, companies can share specific information on "predatory" consultants, quality of local consultants, and differences in rates-information that cannot be obtained through JETRO-making the approval process relatively easier. JETRO's investment coordinator manages negotiations with the development company regarding joint requests made at these meetings. Further, JETRO's Delhi office has opened a business support center that provides advice on Indian investments by an investment coordinator and helps solve a myriad of minor issues that arise from Japanese companies investing in India.

Below is an interview-based overview of the current status of three companies (auto parts maker Company A, auto materials maker Company B, and airconditioning equipment maker Company C) engaging in business in the Neemrana Industrial Park.

\section{Background and Status of Expansion in Neemrana}

- Company A ventured into India as a supplier of brakes, timing their entry to coincide with the release of the Honda City 2008 model. Honda has a factory in Greater Noida; therefore, the company began its search for a property in Noida and areas to the south of Noida along National Highway 8, such as Haryana, Manesar, and Bawal. The industrial park in Bawal was completely sold out as of 2006. The company received word that Phase III of the industrial park in Bawal of approximately 1,100 acres in size would be developed, thus Company A sent a letter to the development company, HISC (Haryana Industrial State Corporation), requesting the purchase of 30 acres. However, the Company A did not receive any response on the tentative time or price of purchasing the property. Subsequently, the company heard of another industrial park being built in Neemrana in the state of Rajasthan. It learned that the cost of property in Haryana was INR 1,800 per square meter, while that in Neemrana was INR 970 per square meter. The company analyzed the distance factor (Manesar was 20-30 min away from Neemrana) and lot size and decided to set up operations in Neemrana because Honda decided to build a factory in Tapukara, located in Rajasthan as well.

- On Company B's entry the Indian market, they selected a site near Delhi in the north, near Honda and Maruti Suzuki, after considering Bawal, Manesar, and Noida, but soon realized that the land suitable for an industrial park was scarce. In coordination with JETRO and RIICO, the company was introduced to Neemrana, an industrial park for Japanese companies, making Neemrana a potential candidate as their location. They selected Neemrana as it was less expensive and clearly defined property rights (provided by the state government of Rajasthan). JETRO being the intermediary to Neemrana, Company B thought of negotiations with the local government as credible.

- After thoroughly analyzing India to set up operations, including Mumbai, Pune, and Bangalore, Company $\mathrm{C}$ found that Neemrana was the only place they could acquire a substantial amount of property on which they could begin construction in the near future. In addition, Company C's Indian sales subsidiary was located in Gurgaon. 


\section{Factory Operations}

- According to Company A, labor employment at Neemrana is inexpensive, despite the expenses such as bus fares for training and commuting. Indian factory worker capacity is not very different from its Chinese counterparts, and Company A considers worker quality as satisfactory. The company uses local suppliers for some raw materials, although most of it is imported from countries like Japan, and aims to increase the percentage of locally sourced parts.

- Before beginning operations in its Neemrana factory, Company B produced materials in Thailand, which it then supplied to a finished goods manufacturer in India. These materials entered the country at the Mumbai port, which were then transported by rail. The company currently imports most of their raw materials, but finds the need locally procure so as to strengthen its future cost competitiveness. The company employs 46 Indians and six Japanese workers, and plans to become more localized by gradually reducing the number of Japanese expatriates. Ceasing operations according to Indian law is complicated for companies with more than 100 employees, inhibiting the company's progress as it considers expansion.

- Company $\mathrm{C}$ procures almost none of its materials locally, but instead imports them from countries such as Japan, Thailand, and China. Thus, the need to begin sourcing them locally is felt; however, they find it difficult to do so because of quality and other issues.

Risk Factors in Indian Industrial Parks and Expansion into the Indian Market

1. Company A was aware of the issues related with electricity, water, and sewerage when it conducted a feasibility study on entering the Indian market. It had already determined and created a budget to prepare and handle such issues.

- According to Company A, several reports must be filed with various departments of the Indian government, and the use of a local consultant is mandatory. Inquiries and requests are compiled during information sharing meetings and are submitted to RIICO. A Japan desk has been created within RIICO, which has proven invaluable by providing a one-stop service.

- Company A also notes that local negotiations are difficult for Japanese companies, making it important to hire quality locals as heads of general affairs and other positions.

- Groundwater was the biggest issue for Company A, the first company to begin operations at the Neemrana Industrial Park. Water shortages were evident with the second company setting operations in the park, and conditions on methods for drawing water, and the amounts they could draw became more stringent. Company A negotiated with the government agency having jurisdiction over water through JETRO and RIICO.

2. Company B conducted a feasibility study before its entry into India, analyzing labor management (union issues), infrastructure (e.g., focusing on electricity and water issues, and incorporating in-house power generation into their plans), and other issues. 
- Company B was not of the notion that water-related issues would pose a potential problem. Because of no wastewater facilities, the company took it upon itself to process its own wastewater, using it in a garden. It thus feels that factories with large amounts of wastewater will have problems. Receiving approvals for water was most cumbersome. Water harvesting regulations required the company to replace groundwater used in excess of the amount of rainfall. However, the region is a desert receiving little rainfall.

- Company B also reports of complicated taxation policies. Cases of double taxation, as well as several different types of taxes, such as duties, state taxes, excise taxes, and inter-state taxes, are imposed and are understood only by Indian consultants. The company has trouble understanding refunds such as incentives.

3. Company $\mathrm{C}$ also notes of a severe water-related problem. They were unaware of rainwater harvesting before setting up operations; however, they are able to comply with regulations because they own an expansive property. All companies in the park have water-related issues, and are working in association with JETRO to resolve them. As a result, RIICO is in the process of constructing a reservoir, and the water stored there will be distributed to each company. In addition, inhouse power generation via diesel is expensive.

\subsection{The Smart Factory Concept at Neemrana Industrial Park}

The DMIC provides a tremendous opportunity to solve infrastructure issues and, as a project of the Indian government supported by the Japanese government, is perceived to be an opportunity to increase commerce in the surrounding area. In the summer of 2008, Hitachi set up a business support center in Delhi to develop new projects in India and also promulgated the concept of a joint energy center within the Neemrana Industrial Park, a joint-use facility to supply electricity to companies in the Park. Electric power supply is constantly constrained within India, and power outages are common lasting for few hours during the course of a day. These circumstances have caused companies at the Park to move toward in-house generation, although the costs to do so are high and can lead to an operational slow down. Also, because water is necessary to run diesel-based, in-house power generation systems, the joint energy center will serve to conserve water.

However, companies operating in the same region have already implemented inhouse power generation equipment, and so a proposal to install and jointly use new gas turbine generators was not adopted. In 2009, Hitachi obtained funding from the New Energy and Industrial Technology Development Organization (NEDO) for research into the feasibility of an interchangeable system to supply stable electric power supply to Indian industrial parks by implementing micro grids and smart grids that would connect approximately 40 in-house diesel power generators (power generating capability of 20,000 kilo watts) where companies may freely share power generated by such a system. 
Ultimately, technical challenges surfaced and it was concluded that deployment of such a system was too complicated. However, Hitachi's efforts have endured as the smart factory concept in the Neemrana Industrial Park. This concept received certification as an "outsourcing project for research on infrastructure export promotion" from the Ministry of Economy, Trade and Industry (METI) in Japan, and with Sumitomo Corporation acting as the managing company, feasibility studies were conducted on three projects: (1) an electric power generation project, (2) a water treatment project, and (3) a logistics project. The power generation project was led by Kansai Electric, and with an anticipated increase in demand for electric power caused by new companies beginning production within the Park, the company is planning an electric and heat supply operation based on a co-generation system using on-site gas turbines (or gas engines). The water treatment project was led by Hitachi, which considered providing a treatment system for on-site wastewater. As a result of the feasibility study, the wastewater treatment project was canceled due to anticipated demand shortages required to make the system economically feasible. However, groundwater levels at Neemrana are found to be dropping, and it is possible that the project would become economically feasible in the event that the Rajasthan government imposed stricter water recovery regulations. The logistics project was led by Nihon Express, which considered a proposal to make logistics both inside and outside of factories more efficient via a milk-run system. However, freight theft is common in India, and implementing the project was deemed as difficult because, among other reasons, procedures to handle theft of goods from multiple companies were complex.

METI outsourced this survey of infrastructure exporting under a system created to promote exports of infrastructure packages, such as electric power and water. Specific projects have been initiated as a result of the Neemrana feasibility studies. Project entities are accumulating the necessary know-how, expected to be laterally expanding to similar projects at other industrial parks. The DMIC is a large-scale regional development project sponsored by both Indian and Japanese governments, and latent demand for electric power and water systems within the Neemrana region alone is thought to be significant. However, companies in the industrial park are required to expand operations within the confines of their own production plans and are not used to moving in tandem with implementing large, joint-use systems to become more efficient. Accordingly, the project entities providing infrastructure must make investments somewhat ahead of the curve, requiring them to forecast demand and ascertain profitability by appropriate means.

\subsection{Significance of This Case Study and Suggested Questions}

This case study was conducted to increase the understanding of operating environments in India from the perspective of manufacturers and cultivate a sense based on actual examples that having friendly relations with local governments (in this case, the government of the state of Rajasthan) is pertinent to expanding businesses 
within developing nations. Further, this case study highlights the support provided by the Japanese government owing to the expansion of automotive parts companies into India, thus influencing the industrial competitiveness of automakers.

Companies in the Neemrana Industrial Park are primarily parts and materials suppliers to local automakers such as Suzuki and Honda; we began our discussion with their expansion into India. However, there are many lessons to be learned from this case study in regards to risk management during a foreign expansion. In addition, the smart factory concept used by industrial parks provides a basis for further consideration of the possibility of infrastructure operations (for example, the complex service operations case study in Chap. 5) in India.

Using this case study, the following questions can be considered to further deepen the understanding of global strategy:

- The Neemrana Industrial Park was created in cooperation between the Indian and Japanese governments. Why did both governments work together on this project? Why is government involvement needed?

- What are the risks for building factories in India? How can companies reduce their risk by locating their facilities within an industrial park, such as the Neemrana Industrial Park?

- The smart factory concept was the subject of a feasibility study sponsored by the Japanese government. Is this project feasible? Detail the feasibilities of electric power, water, and logistics services.

- It is thought that infrastructure services (electric power, water, logistics, etc.) provide extensive business opportunities in India. How should Japanese firms participate in these opportunities?

Open Access This chapter is distributed under the terms of the Creative Commons Attribution Noncommercial License, which permits any noncommercial use, distribution, and reproduction in any medium, provided the original author(s) and source are credited. 